\title{
Diplomacia e fiasco. Repensando a participação brasileira na Liga das Nações: elementos para uma nova interpretação ${ }^{1}$
}

\section{NORMA BREDA DOS SANTOS*}

No prefácio à primeira edição de Vinte anos de crise, publicada em 1939, pouco após a invasão da Polônia por Hitler, E. H. Carr escreve que a "próxima conferência de paz, se não quiser repetir o fiasco da última, terá de se preocupar com assuntos mais fundamentais do que o traçado de fronteiras"2. Por que "fiasco"? Porque, para Carr, a Primeira Guerra Mundial havia sido a expressão da exaustão da ordem liberal “ econômica e política “ do século XIX e o Tratado de Versalhes, produto da ilusão de que a continuidade daquela ordem seria possível. Princípios como o da autodeterminação nacional, do comércio livre e da segurança coletiva, tidos como supostamente absolutos, baseavam-se na idéia liberal de uma natural harmonia de interesses ${ }^{3}$. A diplomacia do entreguerras, incluindo-se aí notoriamente a que se passava no âmbito da Liga das Nações, viveria ainda "vinte anos de crise" para dar lugar a um novo século.

Notava ainda Carr que, com a guerra que se iniciava em 1939, tornava-se "quase inevitável e fácil atribuir a catástrofe às ambições e à arrogância de um punhado de homens, sem buscar uma explicação". No entanto, ponderava, "mesmo quando a guerra já devasta, pode haver mais importância prática numa tentativa de analisar as causas subjacentes e significativas do desastre, do que razões imediatas e pessoais"4.

A busca de "causas subjacentes e significativas" deve também ser tentada para entender um outro fiasco, também geralmente visto na perspectiva da ação de um "punhado de homens": o veto brasileiro à adesão alemã à Liga das Nações, em 1926, e a posterior retirada brasileira da organização internacional.

O conjunto dos estudos brasileiros sobre a participação do Brasil na Liga das Nações é praticamente unânime ao avaliá-la como um fiasco, resultante de motivações notoriamente domésticas. De fato, os quatro anos do mandato presidencial de Artur Bernardes coincidem com um período de forte crítica e abalo das bases de funcionamento da Primeira República, em que grandes fissuras aparecem no sistema político. É nesse 
momento, marcadamente autoritário, que o governo brasileiro concentrará esforços para obter um assento permanente no Conselho da Liga das Nações, fazendo, portanto, apelo à saída utilizada com freqüência por governos que fazem frente a graus acentuados de instabilidade: a busca de objetivos de política externa como artifício para apaziguar movimentos de oposição e desviar a atenção dos problemas de política interna.

O principal objetivo do presente estudo é o de demonstrar que a historiografia brasileira tem magnificado a responsabilidade brasileira nos acontecimentos de março de 1926 na Liga das Nações e que se concentra demasiadamente nas motivações do governo de Artur Bernardes, sem considerar aspectos decisivos concernentes à política internacional, notadamente a européia, e questões de ordem institucional próprias da Liga. Portanto, parece mais do que importante inserir internacionalmente a diplomacia de Bernardes, ou seja, pensá-la no contexto do fiasco da própria diplomacia internacional, dos "vinte anos de crise”.

Por fim, a análise desse episódio pode contribuir para a melhor compreensão do atual momento da diplomacia brasileira junto à Organização das Nações Unidas (ONU), particularmente no que diz respeito à candidatura do Brasil a um assento permanente no Conselho de Segurança.

\section{Os anos na Liga: revisitando o histórico}

\subsection{Os frutos da guerra (1920-1923)}

Dizia um representante britânico, em 1921, que o grande interesse demonstrado pelos brasileiros com relação à Liga das Nações explicava-se "provavelmente não porque têm o menor conhecimento ou interesse pelos problemas europeus atuais, mas simplesmente porque a indicação de brasileiros notáveis para postos importantes no Conselho e na Corte Permanente [de Justiça Internacional] aumenta o orgulho nacional." 5

De fato, se considerações de prestígio não são negligenciáveis para motivar a participação dos países latino-americanos na Liga das Nações, sem interesses vitais a defender em seu âmbito, parece evidente que, no caso do Brasil, a busca do prestígio e a oportunidade que a Liga oferece para alcançá-lo não podem ser negligenciados. Por ter participado na Primeira Guerra Mundial junto aos Aliados, o Brasil torna-se membro fundador da Liga das Nações, iniciando-se, assim, à prática do multilateralismo político e universal, e de todas as novidades que trazia - até então, as Conferências Pan-americanas e a Conferência de Haia de 1907 haviam sido os únicos fóruns internacionais em que havia participado. Mais importante: o Brasil é também indicado para ocupar um dos quatro assentos não permanentes do Conselho da Liga no primeiro ano de funcionamento do órgão, 1920, sendo reeleito para ocupar o mesmo assento continuamente até 1925. 
Essas questões adquirem maior significado quando se tem em mente o contexto histórico vivido pela diplomacia e pela elite brasileira naquele momento. Fazer parte da Liga representa "uma oportunidade única para o Brasil reforçar seu status internacional, contando com o beneplácito das grandes potências”6. Ampliar sua esfera de atuação, saindo dos parâmetros do americanismo, para lançar-se em um empreendimento extracontinental. A sua presença na Liga, portanto, representa um breve interregno universalista, que não deixa em absoluto de estar calcado na visão de um mundo anárquico no qual a diplomacia deve guiar-se pela busca do aumento dos recursos de poder $^{7}$.

O Brasil estabelece, assim, com a Liga uma colaboração regular e mais expressiva do que qualquer outro país latino-americano, como apontado pela historiografia que trata especificamente da Liga das Nações e por autores clássicos, a exemplo de Martin Wight: “Após o Acordo de Paz de 1919, existiam várias potências semigrandes, cada qual querendo ser reconhecida como grande potência. (...) O Brasil, com uma população de tamanho semelhante à da Polônia, era a mais importante potência americana em Genebra, uma vez que os Estados Unidos haviam decidido não fazer parte da Liga."8

Há que se considerar, no entanto, que durante os três anos da presidência Epitácio Pessoa (1919-1922), que coincidem com os primeiros anos de funcionamento da Liga, os delegados brasileiros em Genebra agem com bastante autonomia, podendo ser creditados aos seus esforços espontâneos, e não a instruções recebidas do Rio de Janeiro, os resultados quanto ao que poderia ser de interesse brasileiro na organização internacional ${ }^{9}$. Com relação às bem-sucedidas eleições para o Conselho durante as Assembléias de 1920, 1921 e 1922, o Brasil, como os demais membros temporários do órgão, beneficia-se de circunstâncias momentâneas que têm a ver, notadamente, com a ausência de regras para a renovação desses assentos ${ }^{10}$.

O Pacto simplesmente estabelece em seu artigo $4^{\circ}$ que os assentos temporários do Conselho devem ser "escolhidos livremente pela Assembléia e nos momentos por ela designados”. Em 1921, é aprovada uma emenda ao artigo $4^{\circ}$ do Pacto, estabelecendo a competência da Assembléia para regulamentar o processo de eleição ao Conselho. Dependendo da ratificação de todos os membros do Conselho, a emenda só entra em vigor em 1926, quando a Espanha, então único membro do Conselho que ainda não o fizera, decide ratificá-la. A resistência do governo espanhol em ratificar a emenda ao artigo $4^{\circ}$ torna-se mecanismo de pressão para obter um assento permanente no Conselho, comprometendo a definição dessa questão essencial, ou seja, a fixação de regras para as eleições dos membros temporários do Conselho. Por longo tempo, a Espanha aposta no apoio britânico para alcançar, com exclusividade, um assento permanente no Conselho. Já o Brasil deposita o instrumento de ratificação da emenda junto ao Secretariado da Liga em julho de $1923^{11}$. 
Em 1922, aumenta-se de quatro para seis o número de membros temporários do Conselho e, contrariando diversas recomendações votadas em sessões anteriores, no sentido de que nas eleições dos membros temporários do Conselho fosse adotado o princípio da rotatividade e da distribuição geográfica, vota-se uma recomendação visando a conferir um mandato de três anos aos membros temporários, como forma de assegurar a continuidade de ação do Conselho. Os Estados que tivessem permanecido três anos no Conselho tornarse-iam inelegíveis por igual período, ficando definida uma renovação anual de um terço dos membros eletivos ${ }^{12}$.

Segundo esse sistema, o Brasil deveria ser substituído no Conselho em 1923 - assim como a Espanha e a Bélgica -, o que alteraria totalmente sua situação na Liga. Esse é o contexto que coincide com o começo do mandato presidencial de Artur Bernardes (1922-1926). Com as chances de reeleição ao assento no Conselho fortemente diminuídas, o novo governo estabelece como um dos objetivos de sua política externa a obtenção de um assento permanente no Conselho da $\operatorname{Liga}^{13}$.

1.2. Obter sucesso e a agradar a todos: a impossível fórmula para alcançar o assento permanente

Afrânio de Mello Franco é escolhido por Bernardes para chefiar a delegação brasileira à Assembléia de 1923. Pouco antes de deixar o Rio de Janeiro, Mello Franco recebe de Genebra um relatório pessimista quanto às possibilidades de o Brasil ser reeleito para o Conselho naquele ano. Entre outras questões, o relatório fazia referência às dificuldades de entendimento com os países latinoamericanos. Ou seja, Mello Franco parte para sua missão consciente das dificuldades que iria enfrentar ${ }^{14}$. Parte também com instruções do governo - de Bernardes e de Felix Pacheco, seu Ministro das Relações Exteriores - para buscar criar dois novos assentos permanentes no Conselho, para o Brasil e para a Espanha ${ }^{15}$.

Ao chegar em Genebra, Mello Franco faz alterações nas instruções governamentais. Sugere ao Conselho que um único assento permanente seja criado e ocupado pela Espanha até a entrada da Alemanha. O Brasil ocuparia o assento previsto para os Estados Unidos, mas vago pelo fato de o congresso norteamericano não ter ratificado o Tratado de Versalhes, do qual o Pacto da Liga era um anexo. Sendo a participação norte-americana na Liga cada vez mais remota, Mello Franco vê nesse arranjo uma forma de manter o Brasil no Conselho indefinidamente ${ }^{16}$.

Segundo o próprio Mello Franco, sua fórmula é relativamente bem recebida pelos membros do Conselho, com exceção de Robert Cecil, representante britânico, que se opõe categoricamente ao aumento do número de membros permanentes ${ }^{17}$, 
e do representante espanhol, Quiñonez de León, que declara que seu país jamais aceitaria guardar um lugar para a Alemanha. Mello Franco adapta, então, sua fórmula, sugerindo que a Espanha representasse no Conselho os países hispanoamericanos $^{18}$.

Apesar da resistência do Presidente da República e do Ministro Félix Pacheco às modificações feitas à fórmula original, que previa a criação de dois assentos permanentes para o Brasil e para a Espanha - sobretudo quanto à idéia de o Brasil substituir os Estados Unidos, que poderia ser interpretada como ato de "vassalagem à grande República"19 -, Mello Franco escreve confidencialmente a Robert Cecil, León Bourgeois, representante belga, e Hjalmar Branting, representante sueco, expondo em detalhes sua fórmula. Encontra-se, inclusive, com Cecil, em mais uma tentativa de convencê-lo: fala-lhe da decepção de seu governo com a atitude britânica, maior obstáculo às aspirações brasileiras, e sai do encontro convencido de que a posição britânica havia mudado, já que Cecil prometera examinar "com simpatia” a fórmula brasileira ${ }^{20}$.

O tempo demonstrará o excessivo otimismo de Mello Franco, pois a oposição britânica não desaparece. Pelo menos naquele ano, no entanto, e apesar das recomendações aprovadas em anos anteriores, a Assembléia, a uma única exceção, reelege os membros temporários em exercício. ${ }^{21}$

As crescentes dificuldades para a reeleição ao Conselho fazem com que o governo brasileiro - "segundo círculo diplomático do continente e um dos maiores da atualidade"22, em sua avaliação - se organize melhor para converter os governos estrangeiros à sua causa. Em março de 1924, cria uma embaixada junto à Liga. Afrânio de Mello é nomeado embaixador e Raul Fernandes embaixador em missão especial, com a função de auxiliá-lo. No verão europeu de 1924, Raul Fernandes vai a Londres, Paris, Haia, Praga, Estocolmo e Bruxelas. Dos contatos mantidos, acaba persuadido da justeza das modificações feitas por Mello Franco na fórmula original do governo, pois percebe a resistência européia e dos latino-americanos à idéia de criar-se um assento permanente para o Brasil, e da importância de insistirse sobre o argumento geográfico ou continental, já que existia posição geral favorável a que o Brasil ocupasse o assento dos Estados Unidos (“do continente americano") ${ }^{23}$.

Também em 1924, o governo brasileiro dá início a uma campanha no Brasil, intensificada em 1925, para divulgar seu objetivo de obter um assento permanente no Conselho da Liga, o que passa a ser divulgado nos jornais cariocas pró-governo com muita intensidade. Na época, o embaixador francês no Rio de Janeiro, Alexandre Conty, escreve a Paris repetidas vezes sobre a atenção apaixonada que o Ministro Félix Pacheco demonstra com relação ao papel brasileiro na Liga. O embaixador menciona que "assim que um representante do Brasil se manifestava em Genebra, seu gesto era informado a todos os jornais do Rio de Janeiro (...); as palavras que havia pronunciado eram, assim, reproduzidas por extenso"24. 
A Assembléia de 1924 se realiza sem que a emenda ao artigo $4^{\circ}$ esteja em vigor e reelege ao Conselho o Brasil e os demais cinco países membros temporários eleitos no ano anterior ${ }^{25}$. Mais uma vez os delegados brasileiros têm a satisfação de comunicar ao governo no Rio que o Brasil permanecia no Conselho, mas as preocupações quanto ao futuro acentuam-se, já que uma nova reeleição é tida como totalmente impossível ${ }^{26}$.

\subsection{O problema alemão}

Durante a Assembléia de 1924, o governo alemão encaminha um memorando aos governos com assento no Conselho a fim de consultá-los sobre a adesão da Alemanha à Liga das Nações ${ }^{27}$. Até então, o governo francês mostrarase inflexível com relação ao "perigo alemão", mas com a substituição de Raymond Poincaré por Aristide Briand a adesão da Alemanha tornava-se possível ${ }^{28}$. O memorando objetiva saber se o governo alemão contaria com o apoio do Conselho para aderir à Liga e em que condições a adesão se daria. A admissão acompanhada de um assento permanente no Conselho seria o reconhecimento da condição da Alemanha de grande potência e entrevê o fim de seu isolamento. De todo modo, a adesão sem a concessão do assento permanente no Conselho é vista como intolerável pela opinião pública na Alemanha, onde a Liga das Nações, por ser inseparável do Tratado de Versalhes, é conhecida como "liga dos inimigos"29.

Os governos britânico e francês respondem que tais questões deveriam ser endereçadas à Liga e não tratadas bilateralmente. Adiantam, entretanto, que não fariam objeção a que a Alemanha recebesse um assento permanente no Conselho no momento de sua adesão ${ }^{30}$. O governo brasileiro, por sua vez, afirma que o "Brasil não tem nenhuma objeção a priori à entrada da Alemanha como membro da Sociedade das Nações, [e que] ao contrário, deseja que essa entrada se concretize. Nesse sentido, em princípio, o Brasil não se opõe a que esse novo membro obtenha um lugar permanente no Conselho.” E completa: “o governo do Brasil (...) acha que as questões levantadas com relação aos desejos expressos pela Alemanha são de natureza que não devem ser tratadas de governo a governo mas, de preferência, expostas e discutidas pelo conjunto dos membros da Sociedade e no seio da mesma (...)."31 A resposta utilizava-se, portanto, de termos suficientemente vagos para inspirar dúvidas sobre o apoio brasileiro às condições da adesão alemã.

Em abril de 1925, Régis de Oliveira é nomeado embaixador em Londres. No primeiro encontro oficial com Austen Chamberlain, Ministro britânico dos Negócios Estrangeiros, no dia 26 de abril, dá prioridade à questão da candidatura brasileira ao Conselho. A reação de Chamberlain não apresenta novidade: explica a Régis de Oliveira que todos os países com assento temporário no Conselho haviam apresentado a mesma solicitação e que seu "problema não era defender 
qualquer país, mas sim de justificar uma escolha particular face às reivindicações contraditórias e a necessidade de conservar um equilíbrio entre os membros permanentes e temporários." 32 Meses mais tarde, no dia 30 de julho, o embaixador reencontra Chamberlain, entregando-lhe um longo memorando confidencial que expõe em detalhes o ponto de vista do Brasil sobre a composição do Conselho, memorando que é também enviado aos demais governos com assento no Conselho.

O memorando brasileiro lembra que o Brasil havia ratificado a emenda ao artigo $4^{\circ}$ do Pacto, o que demostrava sua boa vontade com relação à necessidade de estabelecer-se um procedimento quanto à eleição dos membros temporários a Espanha, outra perpétua candidata, ainda não o havia feito -, e que até então, o Brasil havia sido continuamente reeleito para um assento que o próprio Pacto havia-lhe atribuído. Afirma que "a entrada da Alemanha na Liga das Nações [... e sua admissão] como membro do Conselho agravará o desequilíbrio, aliás, já existente, na representação dos diversos continentes nos assentos permanentes do Conselho. Com efeito, enquanto a Europa terá, a partir de então, quatro representantes permanentes no Conselho, a América não terá nenhum. E isso não ocorrerá sem dar aos Estados Unidos o forte argumento em favor de sua tese segundo o qual a Liga das Nações é um instrumento de política européia a serviço de uma aliança entre os governos das grandes potências.” O Brasil não se opõe à permanência da Espanha no Conselho, mas enfatizava que se esse assento lhe fosse acordado, o número de Estados europeus permanentes no Conselho aumentaria ainda mais. Na hipótese da aplicação do sistema de rodízio e da substituição do Brasil por um outro Estado latino-americano, um novo desequilíbrio se criaria, pois, se um assento havia sido atribuído à Espanha, os países hispanoamericanos seriam representados por dois Estados, enquanto o ramo lusófono não teria nenhum representante no Conselho. O memorando busca demonstrar, finalmente, que a "solução mais justa” seria de "manter o Brasil no Conselho por um outro meio que não o sufrágio universal”. Entretanto, “caso se desejasse, com uma flagrante injustiça, fazer prevalecer para a América somente as objeções relativas ao aumento do número de membros permanentes no Conselho (...), deverse-ia manter o assento reservado aos Estados Unidos pelo artigo $4^{\circ}$ e que esse assento seja ocupado provisoriamente pelo Brasil, até que a grande República junte-se novamente à Liga das Nações."33

Em 11 de setembro de 1925, Mello Franco encontra-se com Chamberlain em Genebra. Discutem demoradamente sobre a questão da ampliação do Conselho. Chamberlain reitera o que já havia afirmado ao embaixador Régis de Oliveira e acrescenta que qualquer transformação na composição do Conselho poderia levantar suspeitas por parte da Alemanha no sentido de que as grandes potências visariam criar vozes incondicionais em seu favor. O delegado britânico lembra que representantes da Alemanha estariam presentes à conferência que se reuniria 
dentro de algumas semanas em Locarno, ocasião apropriada para decidir-se sobre o futuro do Conselho ${ }^{34}$.

Viu-se que, em 1924, o governo alemão havia anunciado sua intenção de aderir à Liga e de obter um assento permanente no Conselho, enquanto que o Brasil e a Espanha continuavam a insistir sobre suas reivindicações. As sessões da Assembléia haviam chegado apenas a soluções provisórias, com valor unicamente moral, no sentido de que fosse empregado um sistema de rotatividade e que se observassem as diversidades geográficas. Mais uma sessão acontece, a Assembléia de 1925, sem que a emenda ao Artigo $4^{\circ}$ esteja em vigor, por falta da ratificação espanhola. A Assembléia de 1925 reelege os membros temporários do Conselho em função ${ }^{35}$.

Permanece, portanto, perigosamente, a ausência de regras para eleição dos membros temporários do Conselho, criando uma situação de grande incerteza. De fato, a “[cada] ano, a eleição do Conselho é um espetáculo pouco edificante”36 e a crise de março de 1926 estava em plena maturação.

\subsection{Os (Des)Acordos de Locarno}

Os Acordos de Locarno assinalam a reaproximação franco-alemã, passo considerado decisivo para a segurança no continente europeu ${ }^{37}$. Em Locarno, a diplomacia alemã vê satisfeitas algumas das condições contidas no memorando de setembro de 1924. No que diz respeito ao artigo 16 do Pacto, acorda-se que "cada Estado membro da Liga deve colaborar lealmente e eficientemente para que o Pacto seja respeitado, e opor-se a todo ato de agressão, de forma compatível com sua situação militar e levando-se em conta sua posição geográfica." ${ }^{38}$ Chegase igualmente a um acordo para que a Alemanha seja admitida na Liga na qualidade de grande potência, o que significa que teria um lugar permanente no Conselho ${ }^{39}$. Entretanto, não fica claro se essa entrada se daria com ou sem modificações na composição do Conselho e "o problema da admissão da Alemanha [é] deixado às maquinações dos funcionários exteriores do mundo (...). Quando o Conselho e a Assembléia se reuniram [em 1926], o que aconteceu? Os diplomatas da Europa estavam jogando seu velho jogo de diplomacia secreta, comercializando entre si” 40 .

A opinião pública polonesa exige que a Polônia seja admitida em pé de igualdade e simultaneamente à Alemanha no Conselho: sabia-se que, com sua admissão à Liga, a Alemanha tentaria rever a questão do Corredor de Dantzig e das minorias alemãs na Polônia. Essa admissão era tida como urgente, pois, temiase que, uma vez no Conselho, a Alemanha imporia seu veto a entrada da Polônia.

As negociações de Locarno são concluídas em 16 de outubro de 1925. Alguns dias mais tarde, Mello Franco é recebido por Briand, no Quai D’Orsay. Briand informa que o governo francês já havia notificado oficialmente sua posição no sentido de que o Conselho fosse ampliado não apenas para permitir a participação 
permanente da Alemanha, mas também para a permanência do Brasil, da Espanha e da Polônia. Esse aumento visava a aplicação dos Acordos de Locarno: a presença de países que não haviam participado dos acordos tornaria possível as votações no Conselho no caso em que vários membros se encontrassem impedidos de participar. Briand diz ainda que insistiria junto ao governo inglês a propósito desses pontos $^{41}$.

Mello Franco encontra-se também com Chamberlain, que assegura que, por ocasião da entrada da Alemanha, as candidaturas do Brasil, da Espanha e da Polônia seriam examinadas ${ }^{42}$. Na realidade, no entanto, Chamberlain não havia mudado de opinião, tornando-se simplesmente menos categórico. Quando encontra Régis de Oliveira, no início de dezembro, por exemplo, Chamberlain menciona as dificuldades que estava enfrentando para decidir sobre o que melhor conviria aos interesses do Conselho em razão das reivindicações apresentadas nos últimos meses por diversos países. Afirma também não poder adiantar qual seria sua posição, já que ainda não havia recebido instruções de seu governo. Ao escrever a Ramsay, embaixador britânico no Rio de Janeiro, relatando sua entrevista com Régis de Oliveira, confessa ter sentido "sérias dificuldades para decidir sobre a ação adequada aos interesses do Conselho, e considerando as reclamações que estão aparecendo agora [grifos da autora].”43

O depósito legal dos Acordos de Locarno na Liga, em dezembro de 1925, é comemorado no Conselho com discursos de todos os seus membros. Mello Franco exprime seu desejo de "que o sistema de garantias que fundamenta os Acordos de Locarno pudesse desenvolver-se pouco a pouco e trazer, num futuro próximo, seus frutos ao mundo inteiro" 44 . Entretanto, é importante lembrar que, apenas três meses antes, Raul Fernandes havia pronunciado um discurso, também na Assembléia, no qual declarava que a América não se interessava pelos pactos regionais de segurança e que em sua opinião essa via que tomava a Liga não era a melhor para assegurar a paz mundial ${ }^{45}$.

Em meados de janeiro de 1926, o embaixador da Polônia em Paris anuncia a candidatura de seu país a um assento permanente no Conselho, fato que ocupará cada vez mais espaço na imprensa polonesa, partidária vigorosa da reivindicação ${ }^{46}$. Os encontros de Mello Franco com Briand e Chamberlain ao longo das semanas precedentes ao anúncio antecipavam que a candidatura polonesa seria bem acolhida pela França “ que, naturalmente, favorecia a presença de um aliado seguro no Conselho " e não seria imediatamente rejeitada pela Inglaterra.

De passagem por Paris, em 28 de janeiro, Chamberlain acaba aceitando os argumentos de Briand a favor da reivindicação polonesa e promete expô-los a seu gabinete ${ }^{47}$. Na Inglaterra, a imprensa e o Parlamento opõem-se ao aumento do Conselho, com exceção do assento para a Alemanha ${ }^{48}$. Chamberlain encontra-se também com Quiñonez de Léon nessa ocasião, a quem assegura igualmente seu apoio ${ }^{49}$. 
Abrindo precedentes e admitindo a entrada da Polônia no Conselho e a eventualidade de um aumento no número de assentos permanentes no Conselho, as grandes potências acabam por dar maior força às diversas reivindicações. Em vários países, a opinião pública passa a exercer pressão para que seus governos insistam em receber o mesmo tratamento dado à Polônia ${ }^{50}$. Na Alemanha, em particular, a notícia da candidatura polonesa provoca um grande ressentimento com relação a seus parceiros de Locarno. Luther, chanceler do Reich, afirma publicamente que a Alemanha deveria entrar em um Conselho com a composição existente à época dos acordos. Stresemann declara que as negociações de Locarno haviam levado a Alemanha a tomar a decisão de entrar na Liga, mas tal como ela se encontrava então, e que nada havia sido dito quanto à possibilidade de uma mudança, visto que a estabilidade presumida havia seguramente influenciado a decisão alemã ${ }^{51}$.

\subsection{A possibilidade do recurso ao veto}

Em 8 de fevereiro de 1926, o governo alemão entrega à Liga sua solicitação oficial de admissão ${ }^{52}$. No dia 12, o Conselho reúne-se e decide convocar uma Assembléia Extraordinária para 8 de março, a fim de votar a entrada alemã 53 .

Do Rio de Janeiro, Félix Pacheco e o Presidente Bernardes não se conformam com a exigência alemã de entrada exclusiva no Conselho. O Ministro pergunta a Mello Franco: "até onde no caso poderemos eventualmente usar do direito de veto?"54

O representante brasileiro em Genebra não mudara de idéia com relação ao que afirmava desde 1923: continua preconizando um distanciamento da Liga, caso a solução encontrada representasse uma ofensa ao prestígio do Brasil, ou seja, se o Brasil perdesse seu assento no Conselho. Quanto à questão do veto levantada pelo Ministro, afirma não acreditar ser possível impô-lo contra a Alemanha; acredita, assim, na importância de preservar o pacto de Locarno "no qual a humanidade colocou tanta esperança" 55 . É verdade que as questões tratadas na Liga dizem respeito quase que exclusivamente a interesses europeus, o que, na realidade, permite ao governo brasileiro considerar seu afastamento em diversas ocasiões sem maior cautela.

A realização da Assembléia Extraordinária torna-se iminente sem que questões fundamentais tenham sido resolvidas. Notícias chegam ao Brasil, principalmente sobre a tomada de posições da Grã-Bretanha e da França, alimentando um certo otimismo. Na Grã-Bretanha, apesar de uma moção ser aprovada pela Câmara dos Comuns, em 22 de fevereiro, solicitando ao governo que se oponha à ampliação do Conselho e que apenas aceite a entrada da Alemanha, Chamberlain continua a se mostrar reticente. No dia 23, em discurso feito em Birmingham, declara não ter o governo determinado sua linha de conduta ${ }^{56}$. Além 
disso, Mello Franco informa a Félix Pacheco que havia recebido por intermediário do embaixador Régis de Oliveira uma mensagem confidencial de Chamberlain assegurando que a Grã-Bretanha não havia feito nenhuma promessa particular nem manifestado qualquer oposição específica sobre os assentos do Conselho ${ }^{57}$. A França, por sua vez, não muda de posição: Briand continua a demonstrar seu apoio à candidatura brasileira ${ }^{58}$.

Quanto aos demais governos presentes no Conselho, suas posições apresentam-se basicamente da seguinte maneira: o Japão, em princípio, é contra a ampliação do Conselho. Considerando os acordos de Locarno uma questão sobretudo européia, diz-se, entretanto, pronto a colaborar para sua entrada em vigor e disposto a estudar as demais candidaturas ${ }^{59}$. A Itália está disposta a apoiar o pedido da Polônia e não se mostra contra a reivindicação do Brasil ${ }^{60}$. A Tchecoslováquia é partidária da reivindicação polonesa e aceita que se acordem assentos permanentes à Espanha e ao Brasil. A Bélgica é favorável à candidatura polonesa, deseja a prorrogação de seu assento temporário ou um assento permanente (dependendo do que fosse acordado à Espanha e ao Brasil), mas, sobretudo, está pronta a negociar ${ }^{61}$. A Espanha aceita as candidaturas polonesa e brasileira à condição de ver sua própria solicitação atendida ${ }^{62}$. O Uruguai, que participa do Conselho desde 1922, quer ter seu mandato renovado, o que torna sua posição incerta, ainda que o governo uruguaio comunique ao governo brasileiro sua simpatia pela candidatura do Brasil ${ }^{63}$.

Além dessas reivindicações, a China também apresenta sua candidatura a um assento permanente em 4 de março. A Suécia, por seu turno, persiste em não aceitar a criação de assentos permanentes que não o destinado à Alemanha.

Se, de um lado, parece evidente que o Ministro Félix Pacheco e o Presidente da República dão muita importância à questão da Liga e que estão bastante preocupados, não é menos verdadeiro que o Itamaraty, no "sono letárgico que o caracteriza" 64 , concretamente, ocupa-se muito pouco do problema. As tarefas difíceis são deixadas quase que exclusivamente aos diplomatas brasileiros no exterior, o que certamente contribui para que Pacheco e Bernardes tenham uma visão extremamente superficial dos acontecimentos, sendo movidos pelo sentimento de orgulho nacional e pelas repercussões que o assunto poderia ter no país. Nesse sentido, apesar da insistência de Mello Franco sobre a não utilização do veto contra a Alemanha, o Presidente da República lhe escreve afirmando estar persuadido de que os brasileiros seriam "ludibriados" caso não insistissem em sua entrada no Conselho como membro permanente juntamente com a Alemanha. E continua: "o Brasil não foi ouvido sobre [o] Tratado de Locarno nem sobre [os] compromissos dele oriundos, estando livre portanto para votar como lhe parecer. (...). Em suma: a questão para o Brasil cifra-se em vencer ou não perder."65 [grifo da autora] 
Face ao impasse, Arthur Bernardes e Félix Pacheco transmitem a Mello Franco no dia 7 de março a decisão de que, na ausência de fato novo, o Brasil utilizaria definitivamente seu direito de veto contra a admissão da Alemanha66

Nos dias 7, 10 e 12 de março, os signatários dos acordos de Locarno se reúnem para tentar encontrar um meio de assegurar o êxito à Assembléia Extraordinária. O principal tema de discussões é a entrada concomitante da Alemanha e da Polônia no Conselho.

Na reunião de 7, Stressemann e Luther, Ministro das Relações Exteriores e Chanceler da Alemanha, insistem sobre o fato de que só haviam tomado conhecimento do que se passava oficialmente na Liga das Nações e não do que acontecia nos meios mais restritos. Ou seja, "a Alemanha entraria sozinha no Conselho.(...) Toda [a política do governo] baseia-se nessa tese única (...).”67 Briand e Chamberlain negam ter prometido a entrada exclusiva da Alemanha, insistindo sobre seus compromissos com certas nações que haviam solicitado sua admissão como membros permanentes no Conselho: fala-se principalmente da Polônia e da Espanha e, ainda que raramente, algumas menções são feitas ao Brasil $^{68}$.

No dia 10 de março, o Conselho da Liga reúne-se na residência de Eric Drummond. A Suécia continua a se mostrar firmemente contrária ao aumento do Conselho. A Espanha e o Brasil mantêm-se igualmente firmes em suas antigas reivindicações. Mello Franco lembra que o Brasil não estava ligado aos acordos de Locarno e, pela primeira vez, ameaça claramente vetar a entrada da Alemanha. O Uruguai não manifesta sua posição ${ }^{69}$.

No dia 7 de março, Félix Pacheco havia dado instruções expressas a Mello Franco para utilizar o veto se nada de novo acontecesse. No mesmo dia, Mello Franco havia se encontrado com o Ministro das Relações Exteriores espanhol, que parecia mais aberto à idéia de promover uma ação comum com o Brasil visando à concretização de suas respectivas reivindicações. Yanguas mencionara que seu país resistiria em concordar com a admissão da Alemanha até o último momento, deixando entrever que poderia recorrer ao veto, sem utilizálo realmente no final.

Na reunião locarnista da manhã do dia 12 de março, a idéia de criar uma comissão especial para estudar a questão da reorganização do Conselho é levantada. Propõe-se aos representantes alemães uma fórmula segundo a qual seria criado um assento permanente para a Alemanha e um temporário para a Polônia $^{70}$. Os representantes alemães solicitam tempo para estudar a proposta ${ }^{71}$.

À tarde, Clausel, enviado por Briand, entra em contato com Mello Franco, solicitando seu apoio à fórmula encontrada pelos locarnistas. Mello Franco responde que deve consultar seu governo, mas adianta que o acordo lhe parece impossível, visto que a fórmula proposta acentuava ainda mais o desequilíbrio entre a América e a Europa no Conselho e visava a "colocar a Liga no quadro de Locarno, quando 
Locarno é que deveria ser colocado no quadro da Liga"72.

À noite, tem-se a resposta dos representantes alemães à solução que lhes havia sido proposta: Berlim não aceita o compromisso relativo ao assento não permanente para a Polônia. A realidade é que a opinião pública alemã é contra essa negociação e que o governo alemão poderia cair caso desse a ela seu acordo.

No dia 13 de março, uma nova solução é examinada: um membro temporário do Conselho poderia renunciar em favor da Polônia. A Suécia, querendo contribuir para a concretização dessa solução e disposta a mostrar-se desinteressada, comunica que deixaria o Conselho, cedendo seu lugar à Polônia ${ }^{73}$.

No dia seguinte, Stresemann propõe um novo compromisso, em um artigo publicado nos jornais de Genebra. Insiste sobre a exclusividade da entrada alemã no Conselho e sobre o adiamento da questão da reorganização do órgão para o mês de setembro. Afirma que, uma vez membro da Liga e membro permanente do Conselho, a Alemanha não colocaria obstáculos às decisões relativas à designação de novos membros do Conselho." 74 A proposta sueca, feita na véspera, não é sequer mencionada. Ou seja, os representantes alemães, que em suas declarações oficiais afirmam nada ter contra a presença polonesa no Conselho, encontram-se em situação desconfortável, uma vez que não podem responder publicamente à oferta sueca. Em encontros confidenciais, entretanto, Stresemann e Luther informam que tal sugestão não poderia tampouco ser admitida, pois a composição política do Conselho seria assim modificada de maneira inaceitável para a Alemanha: um governo neutro seria substituído por outro ligado à pequena entente, aliança composta pela Iugoslávia, Tchecoslováquia e Romênia. Os representantes alemães propõem, então, que a Tchecoslováquia fosse também substituída no Conselho por um governo neutro ${ }^{75}$.

Na reunião do Conselho de 15 de março, a Tchecoslováquia anuncia que estaria pronta a renunciar a seu assento ao mesmo tempo que a Suécia para que a Alemanha pudesse dar, finalmente, seu consentimento. A magnanimidade do governo tchecoslovaco não se mostra, no entanto, suficiente para que se saia do impasse: Mello Franco declara que o Brasil mantém seu veto à admissão da Alemanha se não obtivesse também um assento permanente.

\subsection{O veto}

Seria exagero afirmar que nas negociações locarnistas o Brasil havia sido esquecido. Contatos continuavam a ser mantidos com representantes brasileiros. No entanto, essas iniciativas eram modestas demais e desproporcionais ao poder do Brasil de fazer fracassar todas as negociações que não satisfizessem sua pretensão. Somente no dia 15 de março, depois de o Brasil ter anunciado seu veto na reunião do Conselho, Briand e Chamberlain decidem atuar diretamente junto ao governo no Rio de Janeiro. Solicitam a seus representantes no Rio de Janeiro, 
Conty e Beilby Alston, que façam rapidamente uma tentativa conjunta para que Bernardes modifique suas instruções ${ }^{76}$, tentativa bastante tardia visto que, por várias semanas, sabia-se que Mello Franco estava disposto a transigir, mas tinha instruções de seu governo para não fazê-lo.

No dia seguinte, a missão de Conty e Alston se realiza. Ao sair do encontro com o Presidente da República, deixam-lhe sua solicitação por escrito. A solicitação, redigida de maneira a respeitar as suscetibilidades do governo, começa pela afirmação de que o Brasil "não é somente uma grande potência americana, é uma grande potência mundial, que teve um nobre papel na Grande Guerra (...)”. Após sua solicitação propriamente dita, a nota afirma que, se o Brasil consentisse em dar seu acordo a seus amigos europeus, dever-se-ia "render homenagens a sua magnanimidade e a sua grandeza de alma, constatando que está disposto a adiar sua reivindicação legítima, incontestavelmente fundamentada no direito e na lógica" [grifo da autora] a fim de assegurar a paz européia e evitar toda responsabilidade com relação aos problemas da Europa ${ }^{77}$.

Na manhã de 17 de março, horas antes de a Assembléia reunir-se, Mello Franco envia ao Presidente Bernardes um último apelo, a pedido dos países latinoamericanos, para que o governo brasileiro volte atrás em sua decisão. À tarde, tem-se conhecimento do resultado desse último esforço: Mello Franco comunica à Assembléia que seu governo mantém o veto. Em seu discurso lembra os termos da resposta brasileira ao memorando de pedido de admissão do governo alemão de 1924, ou seja, que o governo brasileiro não havia concordado em apoiar a entrada da Alemanha, mas simplesmente estudar essa hipótese no momento devido. Quanto aos acordos de Locarno, afirma que os brasileiros reconheciam sua importância e se felicitavam por essa obra que contribuiria à paz e à justiça na Europa. "Entretanto, por maior que seja o valor deste sistema de acordos (...) não devemos perder de vista que a obra admirável de Locarno deve entrar no quadro da Liga das Nações e não a Liga das Nações na contrução política de Locarno”. Finalmente, informa que as instruções de seu governo são "definitivas e irrevogáveis"78.

\section{As análises sobre a crise de $\mathbf{1 9 2 6}$}

\subsection{A negligência franco-britânica às regras do jogo}

Dois meses depois da Assembléia de março, o embaixador francês no Rio de Janeiro escreve ao Quai D’Orsay fazendo comentários eloqüentes sobre o comportamento de seus colegas em Paris:

No que diz respeito à questão de Genebra, não compreendo por que se ficou surpreso com a atitude e o amor próprio dos brasileiros. (...) Em 6 de outubro de 
1924, o Ministro das Relações Exteriores me disse que não admitia a entrada da Alemanha com um assento permanente no Conselho da Liga a menos que o Brasil também obtivesse, ao mesmo tempo, um assento permanente. Telegrafei, em seguida, ao Departamento. Não se lê meus telegramas? Os classificaram mal? Os que tratam do assunto não conhecem bem os dossiês? Antes da história de 17 de março, Pacheco me havia contado sobre sua pretensão de aumentar o número de assentos permanentes no Conselho antes de admitir a Alemanha. Telegrafei a Paris sugerindo colocar um preço para nossa concordância. Disseram-me para acalmar as ambições federais? Ao contrário. Pediram-me para dizer ao Brasil que teriam nosso acordo por nada. Somente em 16 de março fui convidado a tomar atitude a fim de fazer o Brasil adiar suas pretensões. Não havia nada mais a fazer com [os] dois homens. Bernardes e Pacheco, que nunca estiveram na Europa e a ignoram. Vendo somente que sua política interna é inspirada por seu desejo e sua presunção, provocaram confusão, mas respeitando as regras do jogo. Quando se admite o veto, há que se adiantar para evitá-lo. ${ }^{79}$ [grifo da autora]

A indignação do embaixador francês confirma um importante elemento explicativo da Assembléia de março de 1926: a negligência com que França e Grã-Bretanha trataram as pretensões do Brasil e da Espanha, notadamente, alimentando expectativas de países cuja diplomacia e interesses nacionais encontravam-se fortemente concentrados na luta pela obtenção de um assento no Conselho ${ }^{80}$.

Como explicar tal negligência? A explicação provável está no fato de as lideranças européias viverem, contraditoriamente, com a ilusão de estarem ainda no século XIX, no qual suas diplomacias regulam o mundo, ao mesmo tempo em que as relações diplomáticas no âmbito da Liga reflitam o otimismo do internacionalismo wilsoniano. Ainda que esse otimismo, é verdade, esteja cercado pelos escombros da Grande Guerra e que tenha sido "gradativamente substituído por dúvidas e apreensões que se estenderam pela década de 1930 até desaguarem

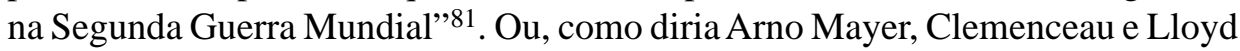
George são homens do século XIX, assim como o são os homens da Liga das Nações. Pensam e comportam-se aristocraticamente. São, antes de mais nada, representantes de uma ordem que resiste à decadência, de uma ordem que dá lugar a ferro e fogo aos valores do capitalismo industrial ${ }^{82}$.

Com efeito, contrariamente ao entendimento comum entre os historiadores, brasileiros incluídos, na passagem do século XIX para o XX a modernidade não triunfa sem contradições: "nem a Inglaterra, nem a França haviam se tornado sociedades civis e políticas industrial-capitalistas e burguesas (...). Suas políticas eram tão 'obviamente antiquadas' e obstinadamente preocupadas com sua 'longevidade' quanto as políticas das outras [potências européias]." ${ }^{83}$ Honra, prestígio, atitudes nobiliárquicas guiam ainda a política européia. A concepção de mundo hierarquizado expressa valores do ancien régime ainda em vigor. Veja-se, 
nesse sentido, o barão do Rio-Branco, que enxerga nos Estados Unidos, com seu desenvolvimento econômico e tecnológico, o parceiro ideal do Brasil, sem abandonar uma admiração inconteste pela cultura e civilização aristocráticas da Europa - França, notadamente.

\subsection{Visões brasileiras}

Os trabalhos sobre a participação do Brasil na Liga das Nações podem ser divididos em dois grupos. O primeiro deles, mais numeroso, engloba os estudos realizados nos anos 1920. No segundo grupo estão trabalhos bem mais recentes, realizados a partir de 1980. Fora desses dois grupos está a obra de Afonso Arinos de Melo Franco, publicado em 1955. Afonso Arinos, que se tornaria Ministro das Relações Exteriores durante o curto governo de Jânio Quadros (janeiro-agosto de 1961) e um expoente da Política Externa Independente, era filho de Afrânio de Mello Franco e aos vinte anos acompanhava seu pai em Genebra. Seu relato não esconde o objetivo de homenagear o pai - que lutava, então, “de um lado contra as intrigas genebrinas, e de outro contra os excessos pugnazes do seu distante governo" 84 - , mas não deixa de considerar fatores que foram, realmente, decisivos para que o Brasil vetasse a entrada alemã na Liga. Ou seja, ainda que em sua avaliação não mencione os já referidos faux pas de Mello Franco, tem em conta, e esta é uma de suas contribuições mais importantes, as intrincadas negociações e pressões das potências locarnistas: "[... M] esmo aqueles que, no fundo, não desejavam sinceramente o convívio dos outros - caso da França com a Alemanha, ou da Alemanha com a Polônia - fingiam-se decepcionados e lançavam, hipocritamente, todo o peso da responsabilidade sobre o Brasil.”85

\subsubsection{O olhar dos contemporâneos}

Os estudos sobre o Brasil e a Liga que datam da década de 1920, de maneira geral, inspiram-se nas posições favoráveis ou contrárias de seus autores com relação ao governo de Artur Bernardes, cujo mandato esteve marcado pela profunda divisão da elite política brasileira, como pode ser claramente percebido nos estudos de José Carlos de Macedo Soares e Elyseo Montarroyos.

Macedo Soares, que se tornaria Ministro das Relações Exteriores (19321933 e 1955-1956), foi o brasileiro contemporâneo à crise que escreveu a mais dura análise sobre a decisão do governo. Era das personalidades mais importantes da oposição a Bernardes. Em dezembro de 1924 escapa da prisão, onde havia ficado dois meses, acusado de envolvimento no levante tenentista de julho em São Paulo. Depois de se refugiar na embaixada argentina, parte para o exílio na Europa, onde estava em março de 1926. Em seu livro, exclusivamente dedicado à participação brasileira na Liga das Nações, atribui a crise de 1926 exclusivamente 
“à hipertrofia criminosa do poder pessoal do Presidente da República” e “a política externa se transformando num vil instrumento de política interna, serve de derivativo às dificuldades da última (...)."

Já Montarroyos participou da Assembléia de 1921 e, em 1924, foi nomeado conselheiro técnico da missão permanente. Em 1926, representou o Brasil na Comissão Encarregada de Estudar a Composição do Conselho, criada pouco após a crise de março. Seu estudo defende claramente a posição do governo Bernardes e critica as potências européias. Afirma Montarroys que

o que se deve ter em conta é que o momento oportuno que o Conselho esperava, assim como havia sido acertado entre seus membros, para proceder à sua própria modificação, iria, finalmente, apresentar-se por ocasião da entrada da Alemanha na Liga das Nações. O Brasil tinha a promessa formal de que sua candidatura teria, então, no Conselho, uma boa acolhida, o que, todos os seus membros, diversas vezes, haviam assegurado. Ora, chegado o momento, o que foi proposto ao Brasil? Que deixasse para mais tarde - às calendas gregas, evidentemente sua pretensão. ${ }^{87}$

\subsubsection{Os estudos recentes}

A participação do Brasil na Liga das Nações ficou por longas décadas sem merecer novos estudos. Só muito recentemente apareceram novas análises, realizadas sobretudo por cientistas políticos e historiadores.

Entre os estudos mais relevantes encontra-se o de Eugênio Vargas Garcia. Utilizando basicamente a troca de correspondência entre Mello Franco, Félix Pacheco e Arthur Bernardes, Garcia busca compreender a percepção desses tomadores de decisão. Com razão, o autor considera que o

excesso de confiança e o voluntarismo que caracterizam toda a campanha [brasileira] desde 1923 remetem a um caso típico de misperception do governo de Artur Bernardes, que superestimou as possibilidades de sucesso de sua aspiração, provavelmente iludido com as mensagens formais de apoio cordial que recebia e confundindo ainda certas particularidades do protocolo diplomático de uma organização multilateral com sinais de reconhecimento da importância do país na comunidade de nações. ${ }^{88}$

Outro importante trabalho é o de Stanley Hilton, que consultou documentos diplomáticos brasileiros e britânicos para escrever sobre a carreira internacional de Afrânio de Melo Franco que, mesmo antes da Revolução de Trinta, quando se torna Ministro das Relações Exteriores - “o Chanceler da Revolução” -, "participara intimamente dos momentos mais dramáticos da diplomacia brasileira, ganhando reputação internacional por seus conhecimentos jurídicos, seu talento como debatedor, e seu savoir faire diplomático geral”"89. Hilton elogia Mello Franco, 
que teria feito incansáveis esforços para sensibilizar seu governo sobre a inconveniência de o Brasil colocar empecilhos à adesão alemã à Liga.

Com seus olhos na opinião pública brasileira, [Bernardes] foi intransigente (...). O que tornou ainda mais amarga a derrota brasileira foi a atitude dos delegados hispano-americanos, que, mostrando (nas palavras de Mello Franco) 'mal disfarçada hostilidade ao Brasil, enviaram um apelo coletivo a Bernardes pedindo que suspendesse o veto e até manifestaram ao Conselho seu desacordo com a atitude adotada pelo Rio de Janeiro. (...) A humilhação final veio quando o Conselho, face à intransigência de Bernardes, nomeou uma comissão para estudar a reorganização do Conselho - ou seja, para encontrar um meio de remover o Brasil - e colocou nela a Argentina (....). ${ }^{90}$

No mesmo sentido vai a análise de Clodoaldo Bueno que entende que

no fundo, a questão não é indagar se era legítima ou não a reivindicação do Brasil (...) e sim se o momento para fazê-la foi o mais oportuno e se o modo de conduzila foi adequado. Mas está fora de dúvida que o governo Bernardes a fez com os olhos voltados para a opinião interna, para angariar prestígio. ${ }^{91}$

Vê-se, pois, que a ênfase desses estudos é colocada no âmbito da política interna e externa brasileira, com maior ou menor aprofundamento documental e analítico. Também, ainda que em diferentes graus, atribuem ao Brasil a responsabilidade de ter prejudicado a política no seio da Liga, buscando uma saída pouco digna e até mesmo humilhante. Ou seja, caracterizam os episódios em torno da retirada brasileira da Liga como um verdadeiro fiasco.

\section{Elementos para uma nova interpretação}

A batalha brasileira pelo assento permanente no Conselho da Liga das Nações encerrou-se melancolicamente. No dia 18 de março de 1926, uma Comissão Encarregada de Estudar a Composição do Conselho era criada. Da Comissão fizeram parte os dez membros do Conselho e mais cinco membros - China, Polônia, Suíça, Alemanha e Argentina. O Brasil participa da primeira sessão de reuniões dessa Comissão, de 10 a 17 de maio, mas não da segunda sessão que aconteceria meses mais tarde, uma vez que o governo brasileiro comunica sua retirada da Liga no dia 10 de junho de 1926.

Com respeito à atuação da diplomacia brasileira durante a campanha ao assento permanente, pelo menos três questões merecem consideração. A primeira delas tem a ver com a clara e sabida susceptibilidade dos países latino-americanos quanto a qualquer pretensão brasileira de querer representá-los. ${ }^{92} \mathrm{~A}$ correspondência de Mello Franco com o Rio de Janeiro está plena de exemplos da falta de apoio das delegações latino-americanas às pretensões brasileiras na Liga. 
O pedido dos países latino-americanos para que o governo brasileiro volte atrás, horas antes da Assembléia do dia 17 de março, expõe definitivamente o terreno movediço em que agiam os diplomatas brasileiros.

Outra questão diz respeito à insistência de Mello Franco para levar a cabo as pretensões de seu governo, retransmitindo ao longo dos anos ao Rio de Janeiro as demonstrações de simpatia que recebe a candidatura brasileira, sem colocar em perspectiva essas manifestações, que muitas vezes pouco tinha a ver com as reais intenções ou possibilidades de seus interlocutores. De fato, essas expressões de apoio são supervalorizadas, contribuindo certamente à atitude de intransigência de Artur Bernardes e Félix Pacheco. Vale notar que em momento algum Mello Franco contrapõe-se decididamente à intransigência do Presidente e do Ministro. Diferentemente, em 1923, na Quinta Conferência Pan-americana (Santiago), chefiando a delegação brasileira, Mello Franco havia ameaçado demitir-se de sua função caso o Ministro Félix Pacheco não respeitasse suas opiniões e cessasse de tomar iniciativas que considerava inadequadas no Rio de Janeiro. ${ }^{93}$

Há que se ressaltar também que, ao longo da campanha ao assento permanente, Mello Franco utiliza argumentos incompatíveis entre si, apresentando primeiramente o Brasil como o substituto legítimo dos Estados Unidos e em seguida como o representante natural dos países latino-americanos. A falta de consistência de seu discurso é a manifestação da própria contradição com que o Brasil se apresentava na Liga, e ainda se apresenta em foros internacionais, defendendo a igualdade jurídica entre os Estados e a democratização das instâncias decisórias internacionais ao mesmo tempo em que busca uma atuação protagônica no âmbito de órgãos restritos daqueles foros.

A campanha brasileira a um assento permanente no Conselho de Segurança da ONU dá sinais de que ainda não se logrou escapar do mesmo tipo de ambigüidade, que pode certamente diminuir seu grau de legitimidade. Nesse sentido, restam algumas questões: a demanda por um assento permanente pode ser interpretada apenas como um desejo de prestígio, isto é, apenas motivada pelo voluntarismo do governo brasileiro e do Itamaraty, em particular? Os formuladores da política externa brasileira estão compreendendo devidamente o que se passa no contexto internacional? Não estariam as grandes potências cometendo equívocos na percepção da atual realidade internacional? A história não se repete, mas tem lições a dar.

Para além de tais questões, viu-se que tanto a política interna e quanto a política exterior brasileira têm importância indiscutível para entender as motivações e atitudes de Bernardes, mas não autorizam a conclusão de que seu governo tenha monopolizado a responsabilidade pela crise de março de 1926 na Liga. Há que se enfocar problemas institucionais que a Liga apresentava, bem como o terreno das relações entre as potências européias, sobretudo França e GrãBretanha. 
Fica patente, portanto, e muito claramente, a importância da consulta a fontes estrangeiras " sobretudo os documentos diplomáticos britânicos e franceses, além da documentação encontrada no Arquivo da Liga das Nações (Genebra)” para compreender os sete anos de participação brasileira na Liga e sua retirada. A política externa brasileira do período está longe de ser suficiente para compreender o que realmente se passava na Liga. Concentrar-se exclusivamente na diplomacia brasileira resulta em uma interpretação equivocada e que tem se resumido à expressão de um "fiasco" brasileiro. Trata-se, na verdade, de um fiasco mais amplo, que tem a ver com a tentativa frustrada de criar, no período pós-Versalhes, uma nova ordem internacional, como bem demonstrado na obra de Carr. A Liga das Nações foi a expressão por excelência dessa tentativa e de seu insucesso. ${ }^{94}$

A Paz de Versalhes e o Pacto da Liga inspiravam-se em uma concepção liberal de mundo que acabou criando um terreno fértil para o exercício do nacionalismo irresponsável que resultou na Segunda Guerra Mundial. Nesse sentido, "[i]nfelizmente, os políticos europeus mais influentes negligenciaram a Liga (...). O racionalismo abstrato ganhou a primeira mão, e [logo no início de funcionamento da Liga], em Genebra, essa corrente levou a Liga decididamente na direção da utopia.” Com efeito,

"[p]oliticamente, a doutrina de interesses em geral tomou a forma de um pressuposto de que as nações possuem um interesse idêntico na paz, e que toda nação que deseje perturbar a paz é, portanto, irracional e imoral. (...) Depois de 1918, foi fácil convencer a parte da humanidade que vive em países de língua inglesa que a guerra não beneficia ninguém. O argumento não pareceu convencer particularmente aos alemães que se beneficiaram bastante nas guerras de 1866 e 1870, e que atribuíram seus mais recentes sofrimentos, não à guerra de 1914, mas ao fato de a terem perdido. Não parecia convencer os italianos, que não culparam a guerra, e sim a traição dos aliados, que os enganaram no acordo de paz. Não convencia também os polacos e tchecoslovacos que, longe de deplorarem a guerra, devem sua existência nacional a ela e nem aos franceses, que não poderiam queixar-se sem reservas de uma guerra que restaurou a Alsácia-Lorena à França (...)." 95

Assim, parece não haver dúvida sobre o fato de que o multilateralismo da Liga das Nações, conforme a idealização de Woodrow Wilson, era inviável na prática. As grandes potências européias, habituadas há séculos com outro jogo político, não cederam às novidades do internacionalismo wilsoniano. ${ }^{96}$

Finalmente, a diplomacia de Mello Franco, Bernardes e Pacheco, com os seus muitos erros e poucos acertos, deve ser colocada em perspectiva, ou seja, deve ser pensada no contexto do "fiasco" da própria diplomacia internacional, dos "vinte anos de crise" ou de exaustão de uma ordem, cujos padrões, eram, em 
grande medida, os do século XIX, a cujos parâmetros a diplomacia brasileira obviamente não escapava.

Outubro de 2003

\section{Notas}

1 A autora agradece a Dácio Malta, Eiiti Sato, Ironildes Bueno e Rogério Farias pela leitura preliminar do presente texto.

2 CARR, E. H. Vinte anos de crise, 1919-1939. 2. ed. São Paulo: Imprensa Oficial do Estado, Brasília: Editora UnB/IPRI, 2001, p. xxxviii.

3 Ibid., p. 21.

$4 \quad$ Ibid., p. xxxvii.

5 Brazil, Annual Report, 1921. In: GRÃ-BRETANHA, British Documents on Foreign Affairs. Reports and Papers from the Foreign Office Confidential Print (BDFA), Part II, Series D, v. 3, p. 64-65.

$6 \quad$ Como lembra Stanley E. HILTON. Brazil and the Post-Versailles World: Elite Images and Foreign Policy Strategy. Journal of Latin American Studies, v. 12, Part 2, 1980, p. 351.

7 Na realidade, tudo indica que prevalece no período uma aguda visão realista e a crença de que valores morais têm muito pouca influência no duro terreno das relações internacionais. Segundo Stanley Hilton “o ingrediente central da Weltanschauung da elite brasileira formuladora da política externa nos anos que seguem a Primeira Guerra Mundial era a convicção de que princípios maquiavélicos guiavam o comportamento internacional dos Estados”. Ibid., p. 342. WIGHT, Martin. A política do poder. 2. ed. Brasília/São Paulo: Editora UnB/IPRI/Imprensa Oficial de São Paulo, 2002, p. 26.

9 BREDA DOS SANTOS, Norma. Le Brésil et la Société des Nations, 1920-1926, tese de doutorado, Institut universitaire de hautes études internationales, Genebra, 1996, p. 166-174.

10 Prevê o artigo $4^{\circ}$ do Pacto que o "Conselho será composto por representantes das Principais Potências Aliadas e Associadas, bem como representantes de quatro outros Membros da Liga. (...) Até a primeira designação pela Assembléia, os representantes da Bélgica, do Brasil, da Espanha e da Grécia serão Membros do Conselho.” Em 1920, Espanha, Brasil e Bélgica são reeleitos. A Grécia é substituída pela China. Em 1921, os quatro países são reeleitos. Em 1922, com a decisão, da Assembléia, de aumentar o número de membros temporários para 6, além da reeleição de Espanha, Brasil, China e Bélgica, são eleitos o Uruguai e a Suécia. Société des Nations (SDN), Actes de la Première Assemblée, 25ème séance plénière, 15/12/1920, p. 559-560; Actes de la Deuxième Assemblée, 33ème séance plénière, 5/10/1921, p. 893894 e 898; Actes de la Troisième Assemblée, 24ème séance plénière, 30/9/1922, p. 383.

11 BRASIL, Relatório apresentado ao Presidente da República (RAPR), 1922-1923, Anexo C, p. 5, e 1923-1924, Anexo C, p. 31-45.

12 SDN, Actes de la Troisième Assemblée, 16ème session plénière, 25/9/1922, p. 224-225.

13 LYRA, Heitor. Minha vida diplomática. Brasília: Editora Universidade de Brasília, 1981, t. 2, p. 1. Antes mesmo de Bernardes assumir seu mandato, a agitação reina em diversos Estados, com a freqüente implicação de setores do exército. O tenentismo é o mais conhecido movimento desse período. “... [A] uma política de moderação (...) - o Presidente esquecerá as injúrias ao candidato, segundo expressão sua - [Bernardes] uma atitude reacionária, simbolizada nas leis repressivas da liberdade de imprensa, no permanente estado de sítio e no desmonte das máquinas dos governos estaduais que lhe tinham sido adversos.” BELLO, José Maria. História da República. 5. ed. São Paulo: Cia. Editora Nacional, 1964, p. 312. 

e seu tempo. Rio de Janeiro: José Olympio Editora, 1955, v. 3, p. 1170.

Ibid., p. 1171.

Mello Franco a Félix Pacheco, 12 e 17/9/1923. BRASIL, Arquivo Histórico do Itamaraty (AHI), 274/2/3.

Mello Franco a Félix Pacheco, 18/9/1923. AHI, 274/2/3.

Mello Franco a Félix Pacheco, 21/9/1923. AHI, 274/2/3.

Félix Pacheco a Mello Franco, 21/9/1923. AHI, 274/2/4.

Mello Franco a Félix Pacheco, 23/9/1923. AHI, 274/2/3.

Assim, são reeleitos em 1923: Bélgica, Brasil, Espanha, Suécia e Uruguai. A China é substituída pela Tchecoslováquia. SDN, Journal Officiel Supplément Spécial, n. 13, Actes de la Quatrième Assemblée, 16 ème séance plénière, 27/10/1923, p. 157.

RAPR, 1924-1925, p. 3.

Raul Fernandes a Mello Franco, AHI, 14/7/1924, e Heitor LYRA, op. cit., t. 2, p. 27.

A. R. Conty ao Ministro dos Negócios Estrangeiros (Paris), 27/11/1924. FRANÇA, Archives diplomatiques françaises (ADF), SDN/Secrétariat général, v. 2022, p. 28-29.

Brasil, Bélgica, Espanha, Suécia, Tchecoslováquia e Uruguai. SDN, Journal Officiel Supplément Spécial, n. 23, Actes de la Cinquième Assemblée, 20 ème séance plénière, $2 /$ 9/1924, p. 116.

Raul Fernandes a Félix Pacheco, 3/10/1924. AHI, 274/2/2.

Memorando da Legação da Alemanha ao Ministério das Relações Exteriores. Rio de Janeiro, 29/9/1924. In: RAPR, 1925-1926, Anexo A, p. 115-118.

Briand renuncia à política de execução do Tratado de Versalhes. Tanto Poincaré quanto Briand acumularam as funções de Primeiro-Ministro e de Ministro dos Negócios Estrangeiros.

Cf. KIMMICH, Christoph M. Germany and the League of Nations. Chicago e Londres: University of Chicago Press, 1976, p. 57-59.

Marquês de Crewe (Paris) a MacDonald, 3/10/1924; Memorandum Respecting the Entry of Germany into the League of Nations, Central Departament, 7/11/1924; Note du Gouvernement français à l'Ambassade d'Allemagne, 6/10/1924. GRÃ-BRETANHA, Foreign Office (FO) 371/9821, p. 112, 195 e 147.

Memorando do Ministério das Relações Exteriores à Representação da Alemanha. Rio de Janeiro, 1/12/1924. In: RAPR, 1924-1925, Anexo A, p. 119-120.

Chamberlain a J. Tilley (Rio de Janeiro), AHI, 27/4/1925 e 6/7/1925. FO, 371/11070, p. 19 e 43-44.

Mello Franco a Pacheco, 3/7/1925, AHI, 274/2/8; Chamberlain a J. Tilley, 6/8/1925. FO 371/ 11070, p. 47-52.

Mello Franco a Félix Pacheco, 12/9/1925. AHI, 274/2/8.

Brasil, Bélgica, Tchecoslováquia, Espanha, Suécia e Uruguai. SDN, Journal Officiel Supplément Spécial, n. 33, Actes de la Sixième Assemblée, 19ème Séance Plénière, 26/9/ 1925, p. 160.

BOVET, Ernest. Les obstacles. A propos de la sixième Assemblée de la Société des Nations. Wissen und Leben, 1925, p. 931.

Pelo papel que desempenharam na negociação desses acordos, Chamberlain, Briand e Stresemann recebem o Prêmio Nobel da Paz: Chamberlain, em 1925; Briand e Stresemann em 1926.

Annexe F aux Accords de Locarno, SDN, A.4.1926 (Extraordinaire) e KIMMICH, Christoph M., op. cit., p. 73.

KIMMICH, Christoph, op. cit., p. 73.

PATTERSON, Caleb P. The Admission of Germany to the League of Nations and its Probable Significance. International Conciliation, n. 231, p. 305 e 310.

Mello Franco a Félix Pacheco, 22/10/1925. AHI, 274/2/9. 
Mello Franco a Félix Pacheco, 29/10/1925. AHI, 274/3/2.

Chamberlain a Ramsay (Rio de Janeiro), 3/12/1925. FO 371/11071, p. 149.

SDN, Procès-verbal de la Trinte-septième Session du Conseil, 7-16/12/1925, p. 181.

SDN, Journal Officiel Supplément Spécial, n. 33, Actes de la Sixième Assemblée, 11ème séance plénière, 15/9/1925, p. 83-84.

BREGMAN, Alexandre, op. cit., p. 16

D’ABERNON. An Ambassador for Peace: Lord D’Abernon's Diary. London, Hodder and Stoughton, s.d., v. III. The Years of Recovery (January 1924-October 1926), p. 231-232. Ver igualmente: RUYSSEN, Theodore. La décade tragique: Genève, 8-17 mars 1926. Paix par le droit, 36e Année, n. 4, abril 1926, p. 159-160.

HARRIS, H. Wilson. Le Conseil sera-t-il augmenté? L'opinion britannique est unanime dans la négation. Journal de Genève, 19/2/1926, p. 1-2.

WALTERS, Francis P. A History of the League of Nations. Westport: Greenwood Press, 1996 (reimpressão), p. 317-318.

D’ABERNON, op.cit., p. 228-229

Pierre de Margerie (Berlim) ao Ministro dos Negócios Estrangeiros (Paris), 13/2/1926. ADF, SDN/Secrétariat général, v. 113, p. 63-64.

SDN, A.4.1926 (Extraordinaire).

SDN, Journal Officiel, 7ème année, n. 4, 38ème session du Conseil , 12/2/1926, p. 498.

Félix Pacheco a Mello Franco, 18/2/1926. AHI, 274/3/4.

Mello Franco a Félix Pacheco, 17 e 20/2/1926. AHI, 274/3/1e 274/3/4, e Félix Pacheco a Mello Franco, 18/2/1926. AHI, 274/3/4.

Fleauriau (Londres) ao Ministro dos Negócios Estrangeiros (Paris), 25/2/1926. ADF, SDN/ Sécrétariat général, v. 113, p. 175.

Félix Pacheco a Mello Franco, 18/2/1926. AHI, 274/3/4.

Mello Franco a Briand, 247271926, e Domício da Gama a Briand, 18/2/1926. ADF, SDN/ Secrétariat général, v. 113, p. 161 e 99.

Gentil (Tokyo) ao Secretário Geral do Ministério dos Negócios Estrangeiros, 20/2/1926, ADF, SDN/Secrétarait général, v. 53, p.185.

$\mathrm{O}$ fato de Mussolini ao menos não se opor à candidatura brasileira era realmente devido à atitude do Brasil no conflito ítalo-grego, onde havia recebido, no Conselho, apoio do Brasil. Ver BREDA DOS SANTOS, op. cit., p. 90-154.

Points de vue des principaux Etats au regard de l'augmentation des sièges, 5 de março de 1926. ADF, SDN/Sécrétariat général, v. 88, p. 143-145, e MARTIN, William. L’élargissement du Conseil. Journal de Genève, 17/2/1926, p. 1.

De Peretti de la Rocca (Madri) a Briand, 3/3/1926. ADF, SDN/Secrétariat général v. 121, p. 62-63.

Félix Pacheco a Mello Franco, 18/9/1925. AHI, 274/3/3.

Nas palavras de Heitor LYRA, op. cit., t. 2, p. 116.

Arthur Bernardes a Mello Franco, 5/2/1926. AHI, 274/3/4.

Félix Pacheco a Mello Franco, 7/3/1926. AHI, 274/3/4.

Réunion du Dimanche, 7/3/1926 (très confidentiel). ADF, SDN/Secrétariat général, v. 121, p. 160.

Ibid., p. 154-164.

Mello Franco a Félix Pacheco, 9 e 11/3/1926. AHI, 274/3/1.

Réunion de 12/3/1926 (très confidentiel). ADF, SDN/Secrétariat général, v. 121, p. 200.

Ibidem.

Mello Franco a Félix Pacheco, 13/3/1926. AHI, 274/3/1.

BREGMAN, Alexandre, op. cit., p. 21. 
Assemblée de la Société des Nations. La crise du Conseil. Une déclaration de M. Stresemann. Journal de Genève, 14/3/1926, p. 2.

KIMMICH, Christopher, op. cit., p. 83 e 84, e BREGMAN, Alexandre, op. cit., p. 21

Briand a Conty, 15/3/1926. ADF, SDN/Secrétariat général, v. 121, p. 232-233.

Note remise le 16 mars au président de la République des Etats-Unis du Brésil par les ambassadeurs de France et d'Angleterre. ADF, SDN/Secrétariat général, v. 126, p. 83-88 e 89-90.

No dia 12 de junho de 1926, o Brasil notifica ao secretariado da Liga sua retirada da organização internacional. SDN, Journal Officiel Supplément Spécial, n. 42, Actes de la Session Extraordinaire de l’Assemblée (Março 1926), 3ème session plénière, 17/3/1926, p. 25-26, e Texto do discurso pronunciado ontem em francês perante a Assembléia Extraordinária das Liga das Nações pelo Chefe da Delegação do Brasil, AHI, sem numeração.

Extrait d'une lettre particulière de M. Conty a M. Dejean, 8/3/1926. ADF, SDN/Secrétariat géneral, v. 2022, p. 4-5.

Os comentários da imprensa britânica e francesa nos dias que seguem à Assembléia não deixam a questão passar em branco, concentrando-se em críticas à política de Chamberlain e Briand. Na imprensa britânica, por exemplo, o Daily News, o Westminster Gazette e o Daily Herald pedem a demissão de Chamberlain. Na França, o Journal, o Ere Nouvelle, Petit Journal, Echo de Paris, o Figaro e o Temps falam do "fracasso" na Liga e questionam a diplomacia de Briand.

SATO, Eiiti. Prefácio à segunda edição brasileira do livro de CARR, E. H. Vinte anos de crise, 1919-1939, op. cit., p. xxv.

MAYER, Arno. A força da tradição: a persistência do Antigo Regime. São Paulo: Cia. Das Letras, 1990, p. 21.

Ibidem. Ver, ainda, sobre o tema o excelente trabalho de BARACUHY, Braz. Vencer ou perder: a diplomacia brasileira na crise da Liga das Nações (1926), Dissertação apresentada ao Instituto Rio Branco, Brasília, 2003, p. 5-9.

MELO FRANCO, Afonso Arinos de, op. cit., p. 1252.

Nesse sentido, vale a pena transcrever Georges Scelles, eminente jurista, citado por Afonso Arinos, já que sua ponderada análise é das mais referidas pela literatura que trata da crise de março de 1926: "Realmente, a Alemanha, não pode, desta vez, se prestar a uma combinação que respeite até os escrúpulos de sua opinião pública e as conveniências ministeriais de seu governo. Quanto aos sacrifícios da Suécia e da Tchecoslováquia, a sessão ordinária de setembro permitirá recompensá-las, ainda mais que, em se tratando da Pequena Entente, a rotatividade entre os Estados que dela fazem parte é um princípio aceito há muito tempo. Pode-se, pois, considerar, que a solução amadurece e que já podemos nos congratular e felicitar. Um grande peso foi tirado de muitas das costas diplomáticas!”. SCELLES, Georges. Une crise de la Société des Nations, Paris: Les Presses Universitaires de France, 1927, p. 42-43.

MACEDO SOARES, José Carlos de. Le Brésil et la Société des Nations, Paris: A. Pedone, 1927, p. 9 e 14.

Elyseo MONTARROYOS. Le Brésil et la crise de la Société des Nations en 1926. Genebra: Imprimerie Albert Kundig, 1926, p. 13.

GARCIA, Eugênio V. A candidatura do Brasil a um assento permanente no Conselho da Liga das Nações. Revista brasileira de política internacional, a. 37, n. 1, 1994, p. 12 e 20. A dissertação de mestrado do autor, de 1994, foi publicada em 2000: O Brasil e a Liga das Nações (1919-1926). Porto Alegre/Brasília: Editora da Universidade/UFRGS/FUNAG.

HILTON, Stanley. Afrânio de Melo Franco e a diplomacia brasileira, 1917-1943. Revista brasileira de política internacional, a. XXIX, n. 1, 1986, p. 15.

Ibid., p. 21-22.

BUENO, Clodoaldo. In: CERVO, Amado \& BUENO, Clodoaldo. História da política

exterior do Brasil. São Paulo: Ática, 1992, p. 207. Registre-se ainda que José Honório 
Rodrigues e Ricardo Seitenfus referem-se à crise de março como uma “catástrofe anunciada”, cuja responsabilidade cabe aos seguidos erros de cálculo da diplomacia brasileira, ou seja, "o obstáculo colocado por provincianos políticos brasileiros”. RODRIGUES, José Honório \& SEITENFUS, Ricardo A. S. Uma história diplomática do Brasil (1531-1945). Organização de Lêda Boechat Rodrigues. Rio de Janeiro: Civilização Brasileira, 1995, p. 330 e 346. Cf. Lámérique latine à Santiago et à Genève. Note préparée par Julian Nogueira pour le Secrétariat général, 20/4/1923, p. 1. SDN, 40/28578/26331, e BREDA DOS SANTOS, Norma, op. cit., p. 209-216.

93 MELO FRANCO, Afonso Arinos de, op. cit., p. 1142-1143.

94 “A Liga das Nações foi um produto do clima ideológico daqueles tempos (...) A figura de Woodrow Wilson dominava a cena ideológica. Aparecia como o profeta de uma nova era, fazendo um apelo dramático aos povos e governos (...). Ao sentar-se à mesa da conferência [da paz], tinha como suporte mais do que o poder americano; tinha apoio no entusiasmo das massas da Europa ocidental que queriam claramente que a ovelha da paz não fosse devorada pelos lobos da diplomacia cínica”. CLAUDE JR., Inis. Swords into Plowshares. The problems and Progress of International. New York: Mc Graw-Hill, 1971, p. 50-51.

95 CARR, E. H., op. cit., p. 42 e 70 . Carr considera que a diplomacia e o direito internacional têm que ser expressão concreta de condições e interesses particulares e não tomados como padrão absoluto (ver, sobretudo, p. 21). Ver também KEYNES, J. M. As conseqüências econômicas da paz. Brasília/São Paulo: Editora UnB/IPRI/Imprensa Oficial do Estado de São Paulo, 2002, e TUCHMAN, Bárbara. A torre do orgulho: um retrato do mundo antes da Grande Guerra, 1890-1914. Rio de Janeiro: Paz e Terra, 1990.

96 Vinte anos após “a guerra para acabar com a guerra”, a criação da ONU tem como contexto uma nova visão liberal. A propósito da questão, salienta Inis Claude que a nova concepção liberal que cria a ONU "refletiu a perda de confiança nos resultados econômicos e políticos do individualismo desprovido de responsabilidade e substitui a fé anterior na mão invisível do mercado, postulada por Adam Smith, pelo planejamento governamental”. CLAUDE JR., Inis, op. cit., p. 78.

\section{Resumo}

O principal objetivo do presente estudo é o de demonstrar que a historiografia brasileira tem magnificado a responsabilidade brasileira nos acontecimentos de março de 1926 na Liga das Nações e que se concentra demasiadamente nas motivações do governo de Artur Bernardes, sem considerar aspectos decisivos concernentes à política internacional, notadamente a européia, e questões de ordem institucional próprias da Liga. Portanto, parece mais do que importante inserir internacionalmente a diplomacia de Bernardes, ou seja, pensá-la no contexto do fiasco da própria diplomacia internacional, dos "vinte anos de crise".

\section{Abstract}

The main objective of the present study is to demonstrate that the Brazilian historiography has magnified the Brazilian responsibility in the events of March 
1926, in the League of Nations. It overconcentrates on the motivations of the government of Artur Bernardes, without considering decisive aspects related to the international politics, specially the European international politics, and institutional issues of the League itself. Thus, it seems more important to look the Brazilian diplomacy from an international perspective, that is, to think about it in the context of the "fiasco" of international diplomacy itself, in the time of "the twenty years crisis".

Palavras-chave: Liga das Nações; Governo Artur Bernardes; Diplomacia brasileira; Diplomacia internacional.

Keywords: League of Nations; Government of Artur Bernardes; Brazilian diplomacy; International diplomacy. 